Meta

Journal des tradlucteurs

Translators' Journal

\title{
Terminologie française
}

\section{Paul A. Horguelin}

Volume 13, numéro 3, septembre 1968

URI : https://id.erudit.org/iderudit/003105ar

DOI : https://doi.org/10.7202/003105ar

Aller au sommaire du numéro

Éditeur(s)

Les Presses de l'Université de Montréal

ISSN

0026-0452 (imprimé)

1492-1421 (numérique)

Découvrir la revue

Citer cet article

Horguelin, P. A. (1968). Terminologie française. Meta, 13(3), 136-137.

https://doi.org/10.7202/003105ar

Ce document est protégé par la loi sur le droit d'auteur. L'utilisation des services d'Érudit (y compris la reproduction) est assujettie à sa politique d'utilisation que vous pouvez consulter en ligne.

https://apropos.erudit.org/fr/usagers/politique-dutilisation/
Cet article est diffusé et préservé par Érudit.

Érudit est un consortium interuniversitaire sans but lucratif composé de l’Université de Montréal, l'Université Laval et l'Université du Québec à Montréal. Il a pour mission la promotion et la valorisation de la recherche. https://www.erudit.org/fr/ 


\section{TERMINOLOGIE FRANÇAISE}

Le Département des sciences économiques de l'Université de Montréal a publié récemment, sous le titre de Terminologie française, un petit lexique des termes économiques et financiers. On y trouve un bon vocabulaire de base, complété dans certains cas par des explications qui aident à mieux saisir le sens d'un terme. C'est ainsi qu'on note avec intérêt la distinction entre investissement - "opérations consistant à créer de nouveaux capitaux réels 》 - et placement - terme réservé aux « opérations consistant à affecter des capitaux monétaires à des emplois lucratifs quelconques $\gg$. Funded debt est définie de la façon suivante: "dette sous forme d'obligations à long terme, pouvant même aller jusqu'à une dette perpétuelle (correspondant à un prêt à fonds perdus), non exigible, dont l'emprunteur ne paye que les intérêts ». À l'article «endossé », on précise que ce terme, «utilisé au Canada, n'a pas strictement cette signification en français international»; on dit plutôt « revêtu de signatures ou avalisé ».

1. Cité par Pierre Daviault, dans Langage et traduction, Ottawa, Imprimeur de la Reine, 1961, p. 37. 
Le point faible de la plupart de ces lexiques spécialisés est de trop souvent donner un seul équivalent pour un terme qui en comporte plusieurs. Par exemple, il est vrai que fiscal peut se traduire par fiscal, mais aussi et plus souvent par financier, budgétaire, de la trésorerie et même douanier ${ }^{1}$. Quelques brefs exemples donnant le contexte permettraient d'éviter cet écueil. Comme beaucoup d'autres, les auteurs du lexique ont achoppé au mot corporation. Ils proposent bien entendu le faux ami "corporation", mais aussi «société anonyme», terme tout aussi fautif au Canada puisque notre droit commercial ne reconnaît pas ce genre de société. Une corporation est dans la plupart des cas une société commerciale ou compagnie. Les fringe benefits n'ont aucun rapport avec les «bénéfices marginaux $\gg ;$ ce sont des avantages sociaux, aussi appelés salaire indirect ou sursalaire et, du point de vue de l'employeur, charges sociales. Dans un pays où les domestiques (pardon, les gens de maison!) sont assez rares, il est surprenant de voir le nombre de personnes qui reçoivent encore des « gages" (wages). Salaries and wages ne se traduisent pas par «salaires et gages », comme on le lit dans le lexique, mais par traitements et salaires. On s'étonne également que des économistes ne fassent pas la distinction entre papier-monnaie et monnaie de papier: à nouveau, les auteurs du lexique auraient pu consulter avec profit Langage et traduction de Pierre Daviault.

À lire certains articles de la Terminologie française, on pourrait croire que les francophones sont vraiment des gens anormaux, vu qu'ils n'ont pas dans leur langue de termes aptes à traduire schedule («barème ?, cédule ? - cette expression «schedule»n'est ordinairement pas employée dans les textes d'économique en français »), lobby, lobbying, lobbyist («expressions non traduites actuellement en français - peut être [sic] nouvelle acception du terme "coulissier»), Welfiare State ( « désigne l'état [sic], le gouvernement, qui entreprend un certain nombre d'activités dans l'ordre économique et social - littéralement l'état du bien-être »)! Le dictionnaire Harrap propose l'État social et, dans un sens ironique, l'État providence.

En conclusion, répétons que l'établissement d'un glossaire exige la participation de spécialistes et de linguistes. Sans cette collaboration, et à défaut d'un contrôle exercé par un organisme gouvernemental ou professionnel, nous sommes condamnés à l'imprécision du vocabulaire et donc à la confusion des esprits.

Paul A. Horguelin

1. Cf. Pierre Daviault, Langage et traduction, Ottawa, Imprimeur de la Reine, 1961. 